psychopharmacology. Amongst the 26 chapters, general reviews, accounts of clinical experiences, more elaborate clinical studies, and reports on experimental work of various degrees of complexity may be found.

The chapters surveying present knowledge cover the treatment of infections of the nervous system with vaccines, sera and antibiotics, anticonvulsants, drugs used in Parkinsonism and other movement disorders, metabolic defects affecting the central nervous system, hormonal factors-particularly adrenal and thyroid-in psychoses, reserpine, phenothiazines, iproniazid, drug addiction, and opiate antagonists. The topics are dealt with in varying detail. The brief and basic approach used in some of these chapters seems unusual for a gathering of specialized workers.

In most cases, reports on individual research accompany the reviewing contributions. Drs. D. M. Woodbury and D. W. Esplin describe work on the metabolism and pharmacodynamics of anti-convulsant drugs. Dr. K. R. Unna and his colleagues present further evidence in favour of the selective inhibition of spinal interneurones by mephenesin and SKF 1045. Two very instructive chapters by Drs. J. V. Brady and H. E. Lehmann discuss methodological points in the evaluation of drug effects on human and animal behaviour, respectively. They are followed by Dr. S. Wolf's cautionary essay on placebos. The story of 2-dimethylaminoethanol, a presumed precursor of acetylcholine and a central stimulant, is traced from animal experiments to clinical trials in schizophrenics by Drs. H. B. Murphree, E. H. Jenney and C. C. Pfeiffer. EEG studies of the action of phenothiazines are described by Drs. E. K. and K. F. Killam, and of nervous stimulants (here differentiated into energizers and anti-depressants) by Dr. H. E. Himwich. The two articles require careful reading but they repay the effort by giving an insight into the possibilities of EEG techniques even to readers not familiar with the method. A very thoroughly documented and illustrated account of the structural effects of tranquillizers is given by Drs. L. Roizin, C. True and M. Knight. Dr. L. Lasagna has taken up the problem of ' misinformation amongst physicians, perpetuated by textbooks and teaching with regard to hypnotics and sedatives. His own large scale observations and those collected from other doctors have brought him to conclusions which ' disagree with most textbooks.' Dr. L. G. Abood reports further instances of increased ceruloplasmin levels in nervous disease. He has also isolated an unstable adrenaline metabolite which produces psychotic symptoms in animals. Another plasma fraction is blamed for psychotic effects by Dr. R. G. Heath and his group. It has been given the euphonious name 'taraxein,' and produced schizophrenic symptoms in volunteering prisoners and monkeys. The discussions which follow these bold hypotheses are less aggressive than one would have feared. An impressive attempt to explain drug effects at the level of neuro-cellular chemistry and microstructure is made by Drs. R. G. Grenell, L. May, W. D.气 McElroy and J. Mendelson. The series is con- 3 cluded by Dr. T. R. Robie's hopeful report on the $\stackrel{\AA}{\varrho}$ use of iproniazid in melancholia.

The discussions of papers are an integral and $\vec{\Rightarrow}$ useful part of books of this type. In this volume chapters are often discussed in groups, which means? that pertaining remarks have to be located in some cases.

\section{ANESTHESIA FOR INFANTS AND CHILDREN}

By Robert M. Smith, M.D. Pp. 418. St. Louis : $\overrightarrow{\vec{\omega}}$ The C. V. Mosby Co. Distributed in Great Britain by Henry Kimpton, London. 90 s.

Dr. Smith's extensive experience of paediatric anaesthesia has enabled him to write a valuable work on the subject. Practically every aspect of ${ }_{A}^{\circ}$ the management of these small patients is discussed $\vec{\omega}$ in detail, emphasis being rightly placed on the importance of a sound knowledge of infant and child ${ }_{\infty}$ physiology. Prominence is also given to descrip-ó tions of disease processes and their implications too the anaesthetist; indeed, this is a particularly. pleasing aspect of the book that is likely to prove ${ }_{z}$ very helpful to the reader seeking knowledge of lesso commonly performed operations. So far as anaesthesia is concerned, Dr. Smith's preference for inhalational anaesthesia in a closed system and wio spontaneous respiration predominates, while theO use of muscle relaxants with controlled respirat receives less favour than it would perhaps fromo a British author. These pages do, however, contains much excellent practical advice on the art of anaesthesia and, after reading them, few will beo able to doubt the importance of special experience in this interesting branch of anaesthesia. This is an excellent book, well produced and amply응 illustrated and can be thoroughly recommended

\section{FORENSIC MEDICINE, OBSERVATION AND INTERPRETATION}

By A. KeIth Mant, M.D.(Lond.). Pp. $262 \frac{3}{3}$. London: Lloyd Luke Ltd. I 959. $42 \mathrm{~s}$.

There are already three Scottish, four English and a number of American works on legal medicine, and publishers who are business men must have been persuaded that Mant had something in theo nature of 'a new work' on the subject before. accepting it. He has, for this little book makes ano entirely practical approach, confining itself to the duties of the doctor, police or coroner's officer and C.I.D. man ' at the scene.' 'Observation and Interpretation' are indeed its key notes, and the author has managed to adhere strictly to the tasko he set for himself. This is a concise, practical ando well illustrated survey from a man of considerable experience of the approach to the body in cases of suspicious or violent death-and in sex offences $\bar{D}$ what to look for and what to say in order to give the 
police a clear conception of the medical aspects of the case are both set out with a clarity-and in the kind of English that gives pleasure to read.

The main sections are concerned with all kinds of sudden and violent death, including asphyxial and infant deaths by violence, and with sex offences: the author has included a useful chapter on the timing of death. The short section on poisoning is unbalanced, for many common poisons-such as tranquillizers-fail to achieve a mention, whereas thallium (which is practically unknown in this country) achieves a page: carbon monoxide, quite properly, has a chapter but ammonia not a word. Drunkenness will be looked for in vain by many police surgeons, and what the doctor should do with bloodstains, clothing, weapons, fingerprints he may spoil, cups and other utensils, vomit, etc., in poisoning cases is not set out as it should be. It is indeed difficult to select and discard in writing a short book, but to make a work wholly useful one must try to see that it is never consulted in vain. Subsequent editions will undoubtedly fill in some of the gaps that approving readers will demand.

Mant's approach is good, his style and English most readable and the standard of publication excellent. This is, in fact, a most practical little handbook to be commended to the doctor, occasional forensic pathologist and coroner's officer likely to be called upon to assist at the scene of examination of a body dead under suspicious circumstances. It is not a textbook for the student or the ordinary practising doctor, for it deliberately confines itself to medico-legal problems that are in these days the concern of the specialist.

\section{PAIN AND ITCH, NERVOUS MECHANISMS} Ciba Foundation Study Group No. I

Edited by G. E. W. Wolstenholme, O.B.E., M.A., M.B., M.R.C.P. and MAEVE O'CoNNOR, B.A. Pp. viii + 120. London: J. \& A. Churchill Ltd. 1959. I2s. 6d.

This is the first in a new series of publications by the Ciba Foundation, London. Its purpose is to report the proceedings of one-day study groups ' organised in honour and around the work of an eminent member of the Foundation's scientific advisory panel.'

Anatomical, physiological and clinical aspects of pain and itch were discussed under the distinguished chairmanship of Lord Adrian by 20 British, American and European scientists, all of whom were actively concerned with these problems.

Discussing the morphology of peripheral structures serving pain and itch, the Oxford anatomists Drs. G. Weddell, E. Palmer and D. Taylor point out that a constant process of degeneration and regeneration can be detected in these axons. They believe, on the basis of investigations of corneal fibres, that corneal sensibility depends on a central analysis of space-time patterns of activity derived from nerve terminals of low specificity. Professor Y. Zotterman, in whose honour the meeting was convened, traces the history of recording of afferent impulses with which he has been connected since r925. His opinion that pain is specifically subserved by the slow non-myelinated $\delta$ and $\mathbf{C}$ fibres is not shared by W. W. Douglas and J. M. Ritchie. Their results were obtained by studying the interaction of electrical antidromic and sensory orthodromic impulses in cutaneous nerves. A similar technique was adapted by $A$. Iggo to single units of $\mathrm{C}$ fibres. He concludes that several types of $\mathbf{C}$ fibres responding to specific mechanical or thermal impulses can be distinguished. The central sensory pathway was studied at the thalamic level by Dr. G. Gordon, and at the thalamic and cortical level by Dr. S. Landgren. Both the Oxford and the Stockholm worker give the reader an excellent idea of the forbidding difficulties encountered in the interpretation of findings in this field. The role of histamine, proteolytic enzymes and $\mathrm{C}$ fibres in causing itch is reviewed by Drs. R. P. Arthur and W. B. Shelley. Clinical investigations supporting the theory of a central origin of pain in trigeminal neuralgia are reported by Drs. E. Kugelberg and U. Lindblom.

Inevitably, divergent, even contradicting views are expressed on many a point. On a more general line, however, a common note is repeatedly struck: the account of initial hopes of early understanding that had to be abandoned. 'It echoes Lord Adrian's introductory remark: 'It is disappointing that there is still so much to investigate.'

This well produced little book should prove a useful guide to the main current trends of research in this ubiquitous yet elusive problem.

\section{SYNOPSIS OF TREATMENT OF ANO-RECTAL DISEASES}

By Stuart T. Ross, M.D., F.A.C.S., F.I.C.S. Pp. 240, illustrated. St. Louis: The C. V. Mosby Co. Distributed in Great Britain by Henry Kimpton, London. 1959. 48s. 6d.

In his preface Dr. Ross, a past President of the American Proctologic Society indicates that his book is designed for general practitioners, medical students and house officers and with this in mind has omitted consideration of bibliography, statistical data, and anything but a very sketchy discussion of aetiology and pathology.

The introductory chapters on anatomy and physiology, history taking and examination, whilst concise, are lucid and adequate for the purpose. There is much sound advice in the book, but the omission of any critical discussion of the various treatments recommended and of their results reduces its value and interest, giving a cookerybook flavour. Not all the methods recommended find favour in this country; for example quinine and urethane is preferred to phenol in oil for injection of haemorrhoids. The author remains a supporter of the traditional concept of a congenital 